\section{Molecular Syndromology}

\title{
Current Approaches in the Development of Molecular and Pharmacological Therapies in Craniosynostosis Utilizing Animal Models
}

\author{
Martin Rachwalski ${ }^{-d}$ Roman H. Khonsari ${ }^{a, c, d}$ Giovanna Paternoster ${ }^{b, d}$ \\ a Imagine Institute of Genetic Diseases, INSERM U1163, Université Paris Descartes, Sorbonne Paris Cité, Departments \\ of ${ }^{b}$ Pediatric Neurosurgery and ${ }^{\mathrm{C}}$ Maxillofacial and Plastic Surgery, and ${ }^{\mathrm{d}}$ National Reference Center for Craniofacial \\ Anomalies, Hôpital Universitaire Necker-Enfants Malades, Paris, France
}

\section{Keywords}

Cranial suture · Craniosynostosis · FGFR2 - Molecular

therapy $\cdot$ Tyrosine kinase inhibitors

\begin{abstract}
The development of the craniofacial skeleton is a spatial and temporal process where cranial sutures play a role in the regulation of morphogenesis and growth. Disruption of these cellular and molecular interactions may lead to craniosynostosis, the premature obliteration of one or more cranial sutures, yielding skull growth restriction and malformation perpendicular to the affected suture. Facial deformity and various functional CNS anomalies are other frequent complications. Cranial vault expansion and reconstructive surgery remain the mainstay of treatment but pose an elevated risk of morbidity for the infant. While the etiology of nonsyndromic craniosynostosis remains to be deciphered, gain-offunction mutations in FGFR1-3 and TWIST1 were found to be responsible for more than $3 / 4$ of the most commonly encountered craniofacial syndromes. Animal models have been invaluable to further dissect the role of genes within the cranial sutures and for the development of alternative nonsurgical treatment strategies. In this review, we will present various molecular and pharmacological approaches for
\end{abstract}

\section{KARGER}

(C) 2018 S. Karger AG, Basel

E-Mail karger@karger.com

www.karger.com/msy the treatment of craniosynostosis that have been tested using in vitro and in vivo assays as well as discuss their potential application in humans focusing on the case of tyrosine kinase inhibitors.

(c) 2018 S. Karger AG, Basel

The development of the craniofacial skeleton is a spatial and temporal process of patterning, proliferation, and differentiation in which cranial sutures play a role in morphogenesis and growth of the skull. Disruption of these cellular and molecular interactions may lead to craniosynostosis, the premature obliteration of one or more cranial sutures. Craniosynostosis mostly occurs as a prenatal event and is a heterogeneous condition which affects approximately 3.1-7.2 per 10.000 live births, with a reportedly rising prevalence [Lajeunie et al., 1995; Cornelissen et al., 2016]. The majority of cases (79\%) are considered to be nonsyndromic and involve the fusion of a single suture in the following order of frequency: sagittal, metopic, coronal, and lambdoid. As the expansion of the underlying brain perpendicular to the affected suture is restricted, this gives rise to a distinct dysmorphic skull shape resulting in craniofacial deformity and may confer functional CNS abnormalities, learning disabilities, and

Dr. Martin Rachwalski

Imagine Institute of Genetic Diseases, INSERM U1163 Université Paris Descartes, Sorbonne Paris Cité

24 Boulevard du Montparnasse, FR-75015 Paris (France)

E-Mail Martin_Rachwalski@ hotmail.com 
developmental delay. Less commonly (21\%), craniosynostosis may be may also associated with over 180 syndromes. These syndromes (e.g., Apert, Pfeiffer, or Saethre-Chotzen) frequently present with various limb malformations, multi-suture synostosis and exhibit overlapping phenotypes. Morphological and functional consequences can be more severe as compared to the nonsyndromic patients and include, but are not limited to, raised intracranial pressure, chronic cerebellar tonsillar herniation, cognitive impairment, exorbitism, oculo-orbital disproportion, visual impairment, midface hypoplasia, and sleep apnea [Wilkie, 2005; Passos-Bueno et al., 2008]. Due to the clinical complexity of these symptoms, a long-term multidisciplinary treatment in a specialized center is warranted. Treatment options for craniosynostosis are still exclusively surgical and basically involve skull vault osteotomies with posterior and/or anterior expansion as well as various forms of craniofacial osteotomies. Although surgical (e.g., distraction osteogenesis) and anesthesia techniques have steadily evolved, these procedures are still associated with morbidity for the infant such as risk of infection, bleeding, venous air emboli, and brain damage [McCarthy et al., 2012]. In order to potentially develop nonsurgical methods to treat or even prevent craniosynostosis in the future, the origin of premature cranial suture fusion remains to be deciphered. While the cause of nonsyndromic craniosynostosis remains elusive and is likely to be multifactorial involving genetic and environmental components, much progress has been made in the last decades in delineating the molecular cause of syndromic forms of this condition (OMIM) [Wilkie, 2005; Passos-Bueno et al., 2008].

However, it was not until 1993 that Jabs et al. first identified a specific gain-of-function mutation (p.P148H) in the gene coding for the transcription factor MSX2 as a genetic cause in a large family with Boston-type craniosynostosis [Jabs et al., 1993]. Although only one additional mutation in MSX2 could be detected until recently [Florisson et al., 2013], this discovery heralded a new era of research on cranial suture biology. In the following years, numerous gain-of-function mutations in genes coding for fibroblast-growth-factor-receptors (FGFR13 ) as well as in the gene coding for the transcription factor TWIST1 were identified to be causative for syndromic craniosynostosis as well as sporadic cases of nonsyndromic coronal synostosis [Muenke et al., 1994, 1997; Reardon et al., 1994; Rutland et al., 1995; Wilkie et al., 1995; el Ghouzzi et al., 1997; Howard et al., 1997]. In their study, Wilkie et al. [2010] showed that $21 \%$ of children within their cohort had a proven genetic cause for their craniosynostosis, among which included gain-of function mutations in FGFR2 (32\%) and FGFR3 (25\%) and loss-of-function mutations in TWIST1 (19\%). These single-gene mutations are represented in over three-quarters of monogenic diagnoses among which Crouzon, Pfeiffer, Apert, Muenke, and Saerthre-Chotzen syndromes are the most frequently encountered [Wilkie et al., 2010]. With the recent implementation of next-generation sequencing technologies, over 52 genes have been associated with craniosynostosis [Laue et al., 2011; Keupp et al., 2013; Ehmke et al., 2017; Miller et al., 2017]. While treatment of nonsyndromic and mutation-negative patients in most cases does not necessitate more than one operation, this is not the case for mutation-positive patients. Multiple surgical procedures over the course of development are performed to correct for the genetically determined pathological growth inhibition and functional abnormalities. Various studies have confirmed that mutation-positive (FGFR2-3 and TWIST1) patients have a significantly higher reoperation rate for complication such as recurrent intracranial hypertension or sleep apnea as compared to their mutation-negative counterparts [Thomas et al., 2005; Woods et al., 2009; Wilkie et al., 2010]. The invasiveness and morbidity associated with craniofacial surgery in the growing child has drawn the attention of researches to foster the development of biological and pharmacological treatments that might prevent or aid at reducing the frequency of reoperations. In this context, animal models such as mouse, rat, and rabbit have proven to be invaluable to dissect the role of genes in regulating the proliferation, apoptosis, and differentiation of cells within the cranial sutures. In particular, mouse models of FGFR2-related syndromes such as Crouzon syndrome (with the $\mathrm{C} 342 \mathrm{Y}$ substitution, the most common animal model for this condition) have been popular to test molecular and pharmacological targets for the treatment of craniosynostosis [Perlyn et al., 2006].

In this review, we will present these alternative strategies which have been studied in various animal models and discuss their potential to be applied in humans [Holmes, 2012].

\section{FGF/FGFR Signaling}

In humans, 4 highly conserved fibroblast growth factor receptors (FGFRs) and 22 ligands, fibroblast growth factors (FGFs) have been described, which have different patterns of expression, allowing for precise control of
116

Mol Syndromol 2019;10:115-123 DOI: $10.1159 / 000493535$
Rachwalski/Khonsari/Paternoster 
various molecular processes, such as in development and oncogenesis. However, only FGFR1-3 have been found to be involved in osteogenesis and craniosynostosis. The typical FGFR molecule is composed of an extracellular ligand-binding domain with 3 immunoglobulin-like domains (IgI, IgII and IgIII), a single-pass transmembrane (TM) domain, and a split intracellular tyrosine kinase domain. In the presence of heparan sulfate (HS) glycosaminoglycans, FGF binds to FGFR causing dimerization, activation of the intrinsic tyrosine kinase and auto-phosphorylation of multiple tyrosine residues on the receptor. These events result in a subsequent induction of a signaling cascade of further intracellular signaling through several downstream pathways and gene transcription in the nucleus. FGFRs can activate multiple intracellular signaling pathways such as MAPK/ERK, PLCg, and P38 but can also interact with potential downstream targets such as TGFß, BMP, TWIST1, and MSX2 which play a critical role in cranial suture patterning [Ornitz and Itoh, 2001; Itoh and Ornitz, 2004; Eswarakumar et al., 2005]. With regards to craniosynostosis, gain-offunction mutations have been mostly identified in the ligand-binding (IgI, IgII and IgIII) and intracellular tyrosine kinase domains of FGFR2, FGFR3, and FGFR1. Hot-spot mutations in these 3 genes are causative for more than half of all syndromic forms of craniosynostosis such as: Apert (FGFR2, IgII-IgIII [p.S252W; p. P253R]), Crouzon (FGFR2, IgII-IgIII), Pfeiffer (FGFR2, FGFR1 IgII-IgIII-; IgIIIa-IgIII), Baere-Stevenson (FGFR2, IgIIIc-TM [p.S372C; G375C]), Antley-Bixler (FGFR2, IgIIIc;IgIIIc-TM) and Jackson-Weiss (FGFR2, IgII-IgIII; IgIIIa-IgIIIc), Muenke (FGFR3, IgII-IgIIl [p.P250R]), Crouzon with acanthosis nigricans (FGFR3, TM, [p.A391E]) and also in sporadic cases of nonsyndromic coronal synostosis (FGFR2) [Wilkie, 2005; Passos-Bueno et al., 2008].

In the last decade, several research groups have tried to develop strategies to inhibit overactive FGF/FGFR signaling. It appears that direct interference at the ligandbinding site or downregulation of the FGF/FGFR downstream signaling cascade seem currently to be the most promising approach in the development of molecular and pharmacological therapies for craniosynostosis. One of the possible strategies is to modulate protein levels, using a truncated FGFR1 molecule, devoid of a cytoplasmic domain, which prevents FGF2-ligand induced signal transduction leading to impaired downstream MAP kinase activation; this strategy has been investigated in a murine calvaria culture system [Greenwald et al., 2001]. Furthermore, Greenwald et al. [2001] showed that postnatal fu-

Molecular and Pharmacological Therapies in Craniosynostosis sion of the posterior part of the frontal (PF) suture in fetal rats was prevented when this dominant-negative FGFR construct was transfected into the PF sutures in utero. Another group utilized glycosaminoglycans such as HS that are required for FGF-FGFR ligand binding and osteoblastic differentiation. They demonstrated that the manipulation of the concentration levels of HS and FGF, in a dose-dependent manner, antagonized overactivated FGFR signaling in cells transfected with the FGFR2b (S252W) mutation [McDowell et al., 2006; Melville et al., 2010]. In another study, a knock-in gene-targeting approach was employed to substitute 2 amino acids, L424A and R426A, in the juxtamembrane domain of an activated Fgfr2c in a Crouzon mouse model (C342Y). These amino acid substitutions prevented the recruitment and tyrosine phosphorylation of Frs2a (FGF receptor substrate 2), the main docking protein for FGFR2, which resulted in the development of a normal craniofacial phenotype in these mice [Eswarakumar et al., 2006]. In a recent study, Yokota et al. [2014] tested the nanogel delivery of a purified soluble form of FGFR2 carrying the S252W mutation $\left(\mathrm{sFGFR} 2^{\mathrm{S} 252 \mathrm{~W}}\right.$ ) on calvaria tissue cultures of Apert mice. They showed that sFGFR2 $2^{\mathrm{S} 252 \mathrm{~W}}$-impregnated nanogels disrupted FGF2-dependent proliferation, phosphorylation of intracellular signaling molecules, and mineralization of FGFR2 ${ }^{\mathrm{S} 252 \mathrm{~W}}$-overexpressing osteoblasts. Furthermore, coronal suture patency was maintained where $\mathrm{sFGFR} 2^{\mathrm{S} 252 \mathrm{~W}}$ was applied, whereas synostosis was observed where the nanogel devoid of sFGFR2 $2^{\mathrm{S} 252 \mathrm{~W}}$ was administered.

However, the biological effects observed in these culture models are still relatively difficult to interpret and translation and verification of the efficiency of these molecular treatments into in vivo assays is crucial. In another approach, a small hairpin RNA directly targeting the mutant Fgfr2 (S252W) transcripts in an Apert mouse model led to complete restoration of the normal, wildtype phenotype. Normal FGFR2 signaling was achieved by an alteration of the activity of extracellular signal-regulated kinases 1 and 2 (ERK1/2), implicating the gene encoding ERK and the genes downstream of it in disease expressivity [Shukla et al., 2007]. An overview of various molecular and pharmacological in vitro and in vivo treatment modalities is presented in Table 1.

Apart from playing a critical role in craniofacial development, FGFR signaling has also been linked to tumorigenesis. Somatic FGFR point mutations are implicated in various cancer types such as: stomach adenocarcinoma (FGFR1), melanoma (FGFR1, FGFR2), uterine (endometrial carcinoma) (FGFR2), high-grade bladder cancer

Mol Syndromol 2019;10:115-123 DOI: $10.1159 / 000493535$ 
Table 1. Molecular and pharmacological in vitro and in vivo treatment modalities

\begin{tabular}{|c|c|c|c|c|c|}
\hline Model & Condition & Target & Treatment & Effects & Reference \\
\hline $\begin{array}{l}\text { In vitro cells calvaria animal, } \\
\text { WT CD } 1 \text { mice and rats }\end{array}$ & Wildtype & FGFR1 & Dominant negative Fgfr1 & $\begin{array}{l}\text { Prevented fusion of the } \\
\text { posterior frontal suture }\end{array}$ & Greenwald et al., 2001 \\
\hline $\begin{array}{l}\text { In vitro cells calvaria animal, } \\
F g f r 2^{C 342 Y / /} \text { mouse }\end{array}$ & Crouzon syndrome & FGFR2 & $\begin{array}{l}\text { FGFR tyrosine kinase } \\
\text { inhibitor (PLX052) }\end{array}$ & $\begin{array}{l}\text { Prevented premature } \\
\text { fusion of the coronal } \\
\text { suture }\end{array}$ & $\begin{array}{l}\text { Eswarakumar et al., } \\
2006\end{array}$ \\
\hline $\begin{array}{l}\text { In vitro cells calvaria animal, } \\
F g f r 2^{\mathrm{C} 342 \mathrm{Y} / \mathrm{p}} \text { mouse }\end{array}$ & Crouzon syndrome & FGFR2 & $\begin{array}{l}\text { FGFR tyrosine kinase } \\
\text { inhibitor (PD173074) }\end{array}$ & $\begin{array}{l}\text { Prevented premature } \\
\text { fusion of the coronal } \\
\text { suture }\end{array}$ & Perlyn et al., 2006 \\
\hline $\begin{array}{l}\text { In vitro cells calvaria animal, } \\
\text { Fgfr } 2^{P 253 R / p} \text { mouse }\end{array}$ & Apert syndrome & ERK1/2 & MEK1 inhibitor (PD98059) & $\begin{array}{l}\text { Partially prevented } \\
\text { premature fusion of the } \\
\text { coronal suture }\end{array}$ & Yin et al., 2008 \\
\hline $\begin{array}{l}\text { In vitro cells calvaria animal, } \\
F g f r 2^{S 252 W} \text { mouse }\end{array}$ & Apert syndrome & FGFR2 & $\begin{array}{l}\text { Purified soluble form of } \\
\text { FGFR2 }\left(\text { sFGFR2 }^{\mathrm{S} 252 \mathrm{~W}}\right) \text { on } \\
\text { nanogel vehicle }\end{array}$ & $\begin{array}{l}\text { Prevented premature } \\
\text { fusion of the coronal } \\
\text { suture }\end{array}$ & Yokota et al., 2014 \\
\hline $\begin{array}{l}\text { In vivo-animal mouse } \\
\text { model with Crouzon } \\
\text { syndrome }\left(F g f r 2^{C 342 Y / h}\right) \text { and } \\
\text { additional juxtamembrane } \\
\text { mutations }\end{array}$ & Crouzon syndrome & $\begin{array}{l}\text { FRS2A docking } \\
\text { protein- } \\
\text { dependent } \\
\text { FGFR2C }\end{array}$ & $\begin{array}{l}\text { Insertion of additional } \\
\text { L424A and R426A } \\
\text { mutations in mouse model } \\
\text { with Crouzon syndrome } \\
\left(F g f r^{2 C 342 Y / p)} \text { prevents }\right. \\
\text { recruitment and tyrosine } \\
\text { phosphorylation of Frs } 2 \text { a }\end{array}$ & $\begin{array}{l}\text { Prevented premature } \\
\text { fusion of the coronal } \\
\text { suture }\end{array}$ & $\begin{array}{l}\text { Eswarakumar et al., } \\
2006\end{array}$ \\
\hline $\begin{array}{l}\text { In vivo animal mouse } \\
\text { model with Apert syndrome } \\
\left(F g f 2^{S 252 W / p}\right)\end{array}$ & Apert & ERK1/2 & $\begin{array}{l}\text { Intraperitoneal injection of } \\
\text { MEK } 1 / 2 \text { inhibitor (U0126) }\end{array}$ & $\begin{array}{l}\text { Prevented premature } \\
\text { fusion of the coronal } \\
\text { suture and partially } \\
\text { rescued phenotype in } \\
\text { Apert mouse }\end{array}$ & Shukla et al., 2007 \\
\hline $\begin{array}{l}\text { In vivo animal mouse } \\
\text { model with Apert syndrome } \\
\left(F g f r 2^{S 252 W / p}\right)\end{array}$ & Apert syndrome & FGFR2 & $\begin{array}{l}\text { Heterozygous } \\
\text { U6-Fgfr } \\
\text { transgenic mouse mated } \\
\text { with Apert syndrome } \\
\text { mouse }\end{array}$ & $\begin{array}{l}\text { Prevented premature } \\
\text { fusion of the coronal } \\
\text { suture and total rescue } \\
\text { of phenotype in Apert } \\
\text { mouse }\end{array}$ & Shukla et al., 2007 \\
\hline $\begin{array}{l}\text { In vivo animal mouse } \\
\text { model with Beare-Stevenson } \\
\text { cutis gyrata syndrome } \\
\left(\mathrm{Fg} f \mathrm{r}^{+/ \mathrm{Y} 394 \mathrm{C}}\right)\end{array}$ & $\begin{array}{l}\text { Beare-Stevenson c } \\
\text { utis gyrate } \\
\text { syndrome }\end{array}$ & p38 & $\begin{array}{l}\text { Intraperitoneal injection of } \\
\text { p38 inhibitor (SB203580) }\end{array}$ & $\begin{array}{l}\text { Amelioration of skin } \\
\text { abnormalities, no effect } \\
\text { on craniofacial } \\
\text { phenotype }\end{array}$ & Wang et al., 2012 \\
\hline $\begin{array}{l}\text { In vivo animal rabbit model } \\
\text { with bilateral coronal suture } \\
\text { craniosynostosis }\end{array}$ & $\begin{array}{l}\text { Bi-coronal } \\
\text { craniosynostosis }\end{array}$ & TGFß2 & $\begin{array}{l}\text { Neutralizing TGFß2 } \\
\text { antibody after suturectomy }\end{array}$ & $\begin{array}{l}\text { Prevented postoperative } \\
\text { resynostosis of the } \\
\text { coronal suture and } \\
\text { improved intracranial } \\
\text { volume and cranial } \\
\text { vault growth }\end{array}$ & $\begin{array}{l}\text { Mooney et al., 2007a, b } \\
\text { Frazier et al., } 2008\end{array}$ \\
\hline $\begin{array}{l}\text { In vivo animal chimeric } \\
\text { human/nude (athymic) rat } \\
\text { xenotransplant model of } \\
\text { craniosynostosis containing } \\
\text { Crouzon and Apert FGFR2 } \\
\text { mutant human osteoblasts }\end{array}$ & $\begin{array}{l}\text { Apert syndrome } \\
\text { Crouzon syndrome }\end{array}$ & Noggin & rh Noggin & $\begin{array}{l}\text { Prevented premature } \\
\text { fusion of the coronal } \\
\text { suture }\end{array}$ & Shen et al., 2009 \\
\hline $\begin{array}{l}\text { In vivo animal mouse } \\
\text { model with postoperative } \\
\text { resynostosis treated with } \\
\text { suturectomy }\end{array}$ & $\begin{array}{l}\text { Bi-coronal } \\
\text { craniosynostosis }\end{array}$ & Noggin & Cells expressing Noggin & $\begin{array}{l}\text { Inhibited bone } \\
\text { formation }\end{array}$ & Cooper et al., 2009 \\
\hline
\end{tabular}

rh, recombinant human; WT, wild type. 
(FGFR3), and cervical cancer [Helsten et al., 2015]. Intriguingly, somatic FGFR2 mutations which were detected in a molecular analysis of endometrial carcinomas paralleled activating germline mutations that cause Apert, Beare-Stevenson, and other skeletal dysplasia syndromes (hypochondroplasia, achondroplasia, and SADDAN) [Pollock et al., 2007]. Except for a few case reports, there is currently no epidemiological evidence indicating that patients with craniosynostosis with these FGFR mutations are at increased risk of developing cancer [Andreou et al., 2006; Rouzier et al., 2008; McDonell et al., 2015]. It appears that activating FGFR mutations exhibit differential effects depending on the stage of development, the cell lineage, and tissue type in which they occur. Although originally developed as anticancer agents, multiple smallmolecule FGF receptor (FGFR) kinase inhibitors are also currently investigated as potential treatment options for craniosynostosis [Melville et al., 2010]. It was demonstrated that premature suture fusion could be prevented when calvaria cultures from a Crouzon mouse model $\left(\mathrm{Fgfr} 2^{\mathrm{C} 342 \mathrm{Y}}\right.$ ) were treated with the FGFR tyrosine kinase inhibitor PD173074, while bilateral coronal suture fusion occurred in the untreated mutants [Perlyn et al., 2006]. In another study, coronal sutures remained patent when Crouzon ( $\left.F g f r 2 c^{C 342 Y / h}\right)$ mouse calvaria was cultured in the presence of PLX052, a small-molecule inhibitor of FGFR [Eswarakumar et al., 2006]. Similarly, Yin et al. [2008] demonstrated that calvaria obtained from an Apert syndrome $\left(F g f r^{P 253 R}\right)$ mouse model would undergo partial alleviation of premature coronal suture fusion when cocultured with the Erk1/2 inhibitor (PD98059) [Yin et al., 2008]. Shukla et al. [2007] were the first to explore the potential of the MEK1/2 inhibitor U0126 in vivo, in an Apert mouse model. U0126 was injected intraperitoneally into female mice carrying pups with the Fgfr $2^{b / S 252 W}$ mutation. Most of the offspring were phenotypically normal at birth including patent coronal sutures. However, their results were difficult to interpret as these authors observed a marked difference between males and females. In order to obtain the best therapeutic response, it appeared that early drug delivery (postnatal day 5) was crucial to completely reverse the phenotype in males. Female pups exhibited an unstable phenotypic expression after birth, including death independent of the time points of U0126 injection [Shukla et al., 2007]. In a more recent study, a p38 kinase inhibitor (SB203580) was employed to treat mice with a Beare-Stevenson cutis gyrata syndrome, which is characterized by craniosynostosis and epidermal hyperplasia. Although $\mathrm{Fg}_{\mathrm{fr}} \mathrm{2}^{+/ \mathrm{Y} 394 \mathrm{C}}$ mice that received injections with SB203580 in utero had

Molecular and Pharmacological Therapies in Craniosynostosis an amelioration of skin abnormalities, there was no obvious improvement of the skull phenotype [Wang et al., 2012].

\section{TGFß/BMP Signaling}

The TGFß superfamily is composed of more than 2 dozen structurally related signaling molecules that mediate numerous steps in normal development and growth. According to structural and functional criteria, TGFß can be grouped into 2 main classes: (1) TGFßs/activins and (2) bone morphogenetic proteins (BMPs) [Cohen, 2003; de Caestecker, 2004; Rawlins and Opperman, 2008]. Immunohistochemical studies on fused human suture samples revealed that TGFß1, TGFß2, and TGFß3 were differentially expressed in the dura and in the osteoblasts lining the periosteal surfaces of the skull vault bones during and after suture morphogenesis [Roth et al., 1997].

The differential expression patterns of TGFß isoforms in fused and open sutures have been assessed [Opperman et al., 1997; Roth et al., 1997]. During the normal process of posterior frontal suture closure in rats, increased expression of TGFß1 and TGFß2 with a declining level of TGFß3 could be detected, whilst the opposite was noted in patent sutures, where increased immunoreactivity of TGFß3 and downregulation of TGFß1 and TGFß2 was apparent [Opperman et al., 1997]. The effect of alternating TGFß levels has been extensively studied both in vitro and in vivo models [Roth et al., 1997; Opperman et al., 1999, 2000; Chong et al., 2003]. Experiments showed that the addition of the TGFß2 protein or the use of neutralizing anti-TGFß3 antibodies in fetal rat calvaria culture induced suture obliteration with increased cell proliferation before suture fusion. Conversely, coronal sutures were rescued from obliteration by the addition of TGFß3 or by using neutralizing TGFß2 antibodies delivered via a collagen vehicle [Opperman et al., 2002; Moursi et al., 2003]. Consistent with these findings, subperiosteal delivery of TGFß3 in an in vivo New Zealand white rabbit model of familial craniosynostosis rescued coronal sutures from fusion, while in another experiment, local application of anti-TGFß2 antibodies into suturectomy sites prevented postoperative re-synostosis [Chong et al., 2003; Mooney et al., 2007]. It appears that TGFß isomers control the cell proliferation in the suture and the surrounding bone fronts, and therefore, any alteration in the balance between these growth factors affects proliferation and apoptosis, which ultimately determines suture fate [Rawlins and Opperman, 2008]. Additionally, extra-cel-

Mol Syndromol 2019;10:115-123

DOI: $10.1159 / 000493535$ 
lular signal-related kinases (Erk1/2) have been identified as potent downstream modulators of TGFß2. When coculturing embryonic mouse calvaria with TGFß2 in the presence or absence of the Erk1/2 inhibitor PD98059 (PD), Opperman et al. [2006] demonstrated that blocking Erk1/2 not only leads to the downregulation of Erk1/2 expression and phosphorylation, but also results in the disruption of TGFß2-related suture fusion. In a more recent study, Gosain et al. [2009] transfected murine dura cells with a selective siRNA pool to knockdown TGFß1 mRNA transcripts. They showed that mRNA levels of TGFß, FGF2, FGFR1, and TGFR2 were significantly reduced. Although their results indicate that the application of TGFß 1 siRNA may have the potential to change signaling in the mouse dura, which is responsible for suture fusion in vitro, they also noted that the suppression of FGF2 and FGFR1 mRNA was only transient, indicating that there might be cross-talk between TGFß1 and FGF2 signaling, thus necessitating further investigation.

BMPs belong to the extensive TGFß family of growth factors and play several roles in skeletal development [Mooney et al., 2004]. Several investigators have also analyzed the role of BMPs in suture formation. Using in situ hybridization, a group led by Thesleff demonstrated the presence of BMP2, BMP4, and BMP7 in osteogenic bone fronts as well as BMP4 and BMP7 in the suture mesenchyme and underlying dura mater [Kim et al., 1998]. Once the sutures had been formed, expression levels of BMP4 and subsequently BMP2 were found to decline [Kim et al., 1998]. Despite these observations, Warren et al. [2003] hypothesized that BMPs and their antagonist Noggin must play a role in suture morphogenesis. They found Noggin to be expressed in patent coronal, sagittal, and posterior frontal sutures, whilst being downregulated during the process of fusion. Although BMP4 induces Noggin expression, FGF signaling blocks Noggin translation in a dose-dependent fashion, either by direct application of FGF2 or by transfection of osteoblasts with FGFR2 gain-of-function mutations. Finally, overexpression of Noggin using an adenovirus in postnatal mice at day 3 led to abnormal maintenance of the posterior frontal suture. Thus, the authors of this study concluded that overactive FGF/FGFR signaling (as seen in FGFR2 gain-of-function mutations) decreased sutural expression of the BMP antagonist Noggin, leading to increased suture osteogenesis and eventually suture fusion [Warren et al., 2003]. Subsequently, Shen et al. [2009] could demonstrate in their chimeric rat model that coronal sutures remained patent when xenotransplantation with mutant FGFR2 osteoblasts was performed together with co-application of re- combinant human Noggin. To test the long-term effects of Noggin exposure on suture patency in a murine model, a gel-foam scaffold loaded with Noggin and GFP-expressing cells was placed onto the suturectomy sites. However, the effect of Noggin treatment was transient and limited to the initial phase of bone healing and the inhibition was not significant compared with untreated controls 12 weeks after surgery. The authors concluded that either "(1) long-term Noggin exposure was never achieved (e.g., through the death of implanted cells or the loss of Noggin expression in implanted cells); or (2) Noggin treatment, regardless of the duration, only has effects in the initial phases of bone healing" [Cooper et al., 2009]. From these studies, it appears that the understanding of the effects of Noggin gene therapy for the long-term prevention of re-synostosis still require further investigation.

\section{Future Outlook}

Currently the mainstay of craniosynostosis treatment remains surgery. Although in recent years there have been several endeavors undertaken to test agents, utilizing in vitro and in vivo assays, plenty of issues need to be resolved before the implementation of molecular and pharmacological therapies in humans can become a realistic option in future.

In most cases, craniosynostoses are unanticipated at birth and only a few familial forms have been reported. While at least $50 \%$ of craniosynostosis syndromes arise by de novo mutations in FGFR1-3, point mutations in nonsyndromic craniosynostosis, which represent the majority of cases, are only occasionally detected. Although the first GWAS for sagittal synostosis identified 2 significantly associated loci, one located downstream of BMP2 (encoding a ligand in BMP signaling) and the other within an intron of BBS9, the etiology underlying nonsyndromic craniosynostosis remains elusive [Justice et al., 2012]. This also means that at present there is no direct molecular target that could be genetically or pharmacologically tackled.

The FGFR2 mutations that underlie conditions such as Apert syndrome occur at an average rate of $10^{5}$ per male gamete, and their likelihood increases with paternal age [Goriely et al., 2003]. Analysis of various Apert mouse models has shown that coronal suture fusion occurs as an early embryonic event, at embryonic days 13.5-15.5, a gestational period in mice that corresponds to weeks 1012 in humans [Holmes et al., 2009; Melville et al., 2010]. However, there is currently no routine screening proce- 
dure available to identify de novo mutations prenatally. As there is little reason to assume that a fetus has a rare craniosynostosis syndrome, the chance of early detection and potential treatment in utero is challenging [Melville et al., 2010].

Tyrosine kinase inhibitors, originally designed for oncologic applications by targeting aberrant FGFR signaling, currently appear to be the most effective treatment option as documented in various in vitro and in vivo studies (Table 1) [Helsten et al., 2015]. In utero treatment by intraperitoneal injection of tyrosine kinase inhibitor (U0126) into pregnant mice carrying pups with Apert syndrome has been attempted by Shukla et al. [2007]. These authors were not able to rescue the craniosynostosis in all heterozygous mutant pups. Early and continuous delivery of the kinase inhibitor was shown to be essential for the treatment success in male pups, while in females, the phenotypic expression was unstable [Shukla et al., 2007]. An independent confirmation of the findings of this study has not yet been reported. In another study, Wang et al. [2012] injected a p38 MAP kinase inhibitor in utero into mice with Beare-Stevenson syndrome; however, they were unable to rescue the craniofacial phenotype and only partially succeeded in attenuating the skin malformations in this model [Wang et al., 2012]. These experiments clearly indicate that despite a tractable molecular target, there are still many variables involved in the treatment success, such as specificity of the applied agent as well as timing and duration of drug delivery. As there is a lot of cross-talk between activated downstream FGFR signaling pathways, it is unlikely that one agent alone will be sufficient to suppress all syndrome-associated features. Therefore, intrauterine treatment with pharmacological agents such as tyrosine kinase inhibitors may have unpredictable and deleterious effects on the developing fetus. As previously discussed, most craniosynostoses occur as a prenatal event which would require early detection and treatment in utero to be successful. However, there exist multiple reports describing cases of lateonset Crouzon syndrome with progressively developing craniosynostosis after birth [Perlyn et al., 2006]. It is conceivable that in this subset of patients, postnatal application of a tyrosine kinase inhibitor could prevent further suture fusion of the cranial vault, skull base, and midface. Prevention of progressive cranial suture fusion (e.g., pansynostosis) or skull base synchondrosis fusion is especially relevant as these children often require multiple surgeries to correct for intracranial hypertension, ocular proptosis, and maxillary hypoplasia. Postnatal application of tyrosine kinase inhibitors as an adjuvant to surgical ther-

Molecular and Pharmacological Therapies in Craniosynostosis apy could therefore possibly reduce the genetically determined growth disturbances and limit the frequency and/ or invasiveness of surgical interventions [Perlyn et al., 2006]. Without doubt, prenatal safe drug dosage and in utero delivery imposes a greater challenge than postnatal strategies. Nevertheless, the long-term toxicity of TKI in children is unknown. Shukla et al. [2007] demonstrated that continuous application of tyrosine kinase inhibitor (U0126) was required to maintain postnatal phenotypic stability in Apert mice, which however led to lethality among some pups [Shukla et al., 2007]. It is unclear whether drug intoxication or developmental defects associated with the $F g f r^{P 253 R}$ mutation led to the early demise of the pups. Negative side effects from systemic delivery of tyrosine kinase inhibitors have been documented for adult oncologic patients, therefore drug safety remains a major concern and limitation in the application of tyrosine kinase inhibitors in developing infants. Owing to the high costs of drug development, safety monitoring and efficacy testing, it is highly unlikely, that agents that do not have an application in oncology will be specifically designed for infants with rare craniosynostosis syndromes in the near future [Wilkie, 2007]. The exploration of safe drug delivery techniques, ideal dosage, and application timing seem to be the most important issues that need to be tackled to reduce the side effects of the application of systemic tyrosine kinase inhibitors.

\section{Summary}

Although tremendous progress has been already achieved in the last decades, expanded knowledge of the molecular mechanism underlying craniosynostosis is still warranted. The underlying cause of nonsyndromic craniosynostosis still remains to be elucidated, which implies that there is currently no direct molecular target that could be genetically or pharmacologically tackled. On the contrary, animal models of FGFR2-related syndromes have proven to be useful for in vitro and in vivo studies of syndromic craniosynostoses. It appears that direct interference at the ligand-binding site or downregulation of the FGF/FGFR downstream signaling cascade by means of tyrosine kinase inhibitors are the most promising approaches in the development of molecular and pharmacological therapies. At present, an application of these therapies in humans however seems not to be possible, since craniosynostosis mostly occurs as a prenatal event, and no routine screening procedure is available to identify de novo mutations in utero. Postnatal systemic long-

Mol Syndromol 2019;10:115-123

DOI: $10.1159 / 000493535$ 
time drug application with tyrosine kinase inhibitors might potentially have beneficial effects on the craniofacial phenotype. However, its application is limited by the unpredictable and deleterious toxic effects that need to be anticipated in the developing infant. Further research is required to improve prenatal detection techniques and drug safety before biological and pharmacological therapies will become feasible to treat children with craniofa- cial conditions and potentially abrogate the need for surgical intervention in the future.

\section{Disclosure Statement}

The authors have no conflicts of interest to declare.

\section{References}

Andreou A, Lamy A, Layet V, Cailliez D, Gobet F, et al: Early-onset low-grade papillary carcinoma of the bladder associated with Apert syndrome and a germline FGFR2 mutation (Pro253Arg). Am J Med Genet A 140:2245-2247 (2006).

Chong SL, Mitchell R, Moursi AM, Winnard P, Losken HW, et al: Rescue of coronal suture fusion using transforming growth factor-beta 3 (Tgf-beta 3) in rabbits with delayed-onset craniosynostosis. Anat Rec A Discov Mol Cell Evol Biol 274:962-971 (2003).

Cohen MM Jr: TGF beta/Smad signaling system and its pathologic correlates. Am J Med Genet A 116A:1-10 (2003).

Cooper GM, Usas A, Olshanski A, Mooney MP, Losee JE, Huard J: Ex vivo Noggin gene therapy inhibits bone formation in a mouse model of postoperative resynostosis. Plast Reconstr Surg 123 Suppl 2:94S-103S (2009).

Cornelissen M, Ottelander Bd, Rizopoulos D, van der Hulst R, Mink van der Molen A, et al: Increase of prevalence of craniosynostosis. J Craniomaxillofac Surg 44:1273-1279 (2016).

de Caestecker M: The transforming growth factor-beta superfamily of receptors. Cytokine Growth Factor Rev 15:1-11 (2004).

Ehmke N, Graul-Neumann L, Smorag L, Koenig $\mathrm{R}$, Segebrecht $\mathrm{L}$, et al: De novo mutations in SLC25A24 cause a craniosynostosis syndrome with hypertrichosis, progeroid appearance, and mitochondrial dysfunction. Am J Hum Genet 101:833-843 (2017).

el Ghouzzi V, Le Merrer M, Perrin-Schmitt F, Lajeunie E, Benit P, et al: Mutations of the TWIST gene in the Saethre-Chotzen syndrome. Nat Genet 15:42-46 (1997).

Eswarakumar VP, Lax I, Schlessinger J: Cellular signaling by fibroblast growth factor receptors. Cytokine Growth Factor Rev 16:139-149 (2005).

Eswarakumar VP, Ozcan F, Lew ED, Bae JH, Tomé $\mathrm{F}$, et al: Attenuation of signaling pathways stimulated by pathologically activated FGF-receptor 2 mutants prevents craniosynostosis. Proc Natl Acad Sci USA 103:1860318608 (2006).
Florisson JM, Verkerk AJ, Huigh D, Hoogeboom AJ, Swagemakers S, et al: Boston type craniosynostosis: report of a second mutation in MSX2. Am J Med Genet A 161A:2626-2633 (2013).

Goriely A, McVean GA, Röjmyr M, Ingemarsson B, Wilkie AO: Evidence for selective advantage of pathogenic FGFR2 mutations in the male germ line. Science 301:643-646 (2003).

Gosain AK, Machol JA 4th, Gliniak C, Halligan NL: TGF-beta1 RNA interference in mouse primary dura cell culture: downstream effects on TGF receptors, FGF-2, and FGF-R1 mRNA levels. Plast Reconstr Surg 124:14661473 (2009).

Greenwald JA, Mehrara BJ, Spector JA, Warren SM, Fagenholz PJ, et al: In vivo modulation of FGF biological activity alters cranial suture fate. Am J Pathol 158:441-452 (2001).

Helsten T, Schwaederle M, Kurzrock R: Fibroblast growth factor receptor signaling in hereditary and neoplastic disease: biologic and clinical implications. Cancer Metastasis Rev 34:479-496 (2015).

Holmes G: The role of vertebrate models in understanding craniosynostosis. Childs Nerv Syst 28:1471-1481 (2012).

Holmes G, Rothschild G, Roy UB, Deng CX, Mansukhani A, Basilico C: Early onset of craniosynostosis in an Apert mouse model reveals critical features of this pathology. Dev Biol 328:273-284 (2009).

Howard TD, Paznekas WA, Green ED, Chiang LC, Ma N, et al: Mutations in TWIST, a basic helix-loop-helix transcription factor, in Saethre-Chotzen syndrome. Nat Genet 15:36-41 (1997).

Itoh N, Ornitz DM: Evolution of the Fgf and Fgfr gene families. Trends Genet 20:563-569 (2004).

Jabs EW, Müller U, Li X, Ma L, Luo W, et al: A mutation in the homeodomain of the human MSX2 gene in a family affected with autosomal dominant craniosynostosis. Cell 75:443450 (1993).

Justice CM, Yagnik G, Kim Y, Peter I, Jabs EW, et al: A genome-wide association study identifies susceptibility loci for nonsyndromic sagittal craniosynostosis near $B M P 2$ and within BBS9. Nat Genet 44:1360-1364 (2012).
Keupp K, Li Y, Vargel I, Hoischen A, Richardson $\mathrm{R}$, et al: Mutations in the interleukin receptor IL11RA cause autosomal recessive Crouzonlike craniosynostosis. Mol Genet Genomic Med 1:223-237 (2013).

Kim HJ, Rice DP, Kettunen PJ, Thesleff I: FGF-, BMP- and Shh-mediated signalling pathways in the regulation of cranial suture morphogenesis and calvarial bone development. Development 125:1241-1251 (1998).

Lajeunie E, Le Merrer M, Bonaïti-Pellie C, Marchac D, Renier D: Genetic study of nonsyndromic coronal craniosynostosis. Am J Med Genet 55:500-504 (1995).

Laue K, Pogoda HM, Daniel PB, van Haeringen A, Alanay Y, et al: Craniosynostosis and multiple skeletal anomalies in humans and zebrafish result from a defect in the localized degradation of retinoic acid. Am J Hum Genet 89:595-606 (2011).

McCarthy JG, Warren SM, Bernstein J, Burnett W, Cunningham ML, et al: Parameters of care for craniosynostosis. Cleft Palate Craniofac J 49 Suppl:1S-24S (2012).

McDonell LM, Kernohan KD, Boycott KM, Sawyer SL: Receptor tyrosine kinase mutations in developmental syndromes and cancer: two sides of the same coin. Hum Mol Genet 24:R60-66 (2015).

McDowell LM, Frazier BA, Studelska DR, Giljum $\mathrm{K}, \mathrm{Chen} J$, et al: Inhibition or activation of Apert syndrome FGFR2 (S252W) signaling by specific glycosaminoglycans. J Biol Chem 281: 6924-6930 (2006).

Melville H, Wang Y, Taub PJ, Jabs EW: Genetic basis of potential therapeutic strategies for craniosynostosis. Am J Med Genet A 152A:3007-3015 (2010).

Miller KA, Twigg SR, McGowan SJ, Phipps JM, Fenwick AL, et al: Diagnostic value of exome and whole genome sequencing in craniosynostosis. J Med Genet 54:260-268 (2017).

Mooney MP, Losken HW, Moursi AM, Bradley J, Azari K, et al: Anti-TGF-beta2 antibody therapy inhibits postoperative resynostosis in craniosynostotic rabbits. Plast Reconstr Surg 119:1200-1212 (2007). 
Moursi AM, Winnard PL, Fryer D, Mooney MP: Delivery of transforming growth factor-beta2-perturbing antibody in a collagen vehicle inhibits cranial suture fusion in calvarial organ culture. Cleft Palate Craniofac J 40:225232 (2003).

Muenke M, Schell U, Hehr A, Robin NH, Losken HW, et al: A common mutation in the fibroblast growth factor receptor 1 gene in Pfeiffer syndrome. Nat Genet 8:269-274 (1994).

Muenke M, Gripp KW, McDonald-McGinn DM, Gaudenz K, Whitaker LA, et al: A unique point mutation in the fibroblast growth factor receptor 3 gene (FGFR3) defines a new craniosynostosis syndrome. Am J Hum Genet 60:555-564 (1997).

Opperman LA, Nolen AA, Ogle RC: TGF-beta 1, TGF-beta 2, and TGF-beta 3 exhibit distinct patterns of expression during cranial suture formation and obliteration in vivo and in vitro. J Bone Miner Res. 12(3):301-10 (1997).

Opperman LA, Chhabra A, Cho RW, Ogle RC: Cranial suture obliteration is induced by removal of transforming growth factor (TGF)beta 3 activity and prevented by removal of TGF-beta 2 activity from fetal rat calvaria in vitro. J Craniofac Genet Dev Biol 19:164-173 (1999).

Opperman LA, Adab K, Gakunga PT: Transforming growth factor-beta 2 and TGFbeta 3 regulate fetal rat cranial suture morphogenesis by regulating rates of cell proliferation and apoptosis. Dev Dyn 219:237-247 (2000).

Opperman LA, Moursi AM, Sayne JR, Wintergerst AM: Transforming growth factor-beta 3 (Tgf-beta3) in a collagen gel delays fusion of the rat posterior interfrontal suture in vivo. Anat Rec 267:120-130 (2002).

Opperman LA, Fernandez CR, So S, Rawlins JT: Erk1/2 signaling is required for Tgf-beta 2-induced suture closure. Dev Dyn 235(5):1292-9 (2006).

Ornitz DM, Itoh N: Fibroblast growth factors. Genome Biol 2:reviews3005.1-reviews3005.12 (2001).
Passos-Bueno MR, Serti Eacute AE, Jehee FS, Fanganiello R, Yeh E: Genetics of craniosynostosis: genes, syndromes, mutations and genotype-phenotype correlations. Front Oral Biol. 12:107-43 (2008)

Perlyn CA, Morriss-Kay G, Darvann T, Tenenbaum M, Ornitz DM: A model for the pharmacological treatment of crouzon syndrome. Neurosurgery. 59(1):210-5 (2006).

Pollock PM, Gartside MG, Dejeza LC, Powell MA, Mallon MA, et al: Frequent activating FGFR2 mutations in endometrial carcinomas parallel germline mutations associated with craniosynostosis and skeletal dysplasia syndromes. Oncogene. 26(50):7158-62 (2007).

Rawlins JT, Opperman LA: Tgf-beta regulation of suture morphogenesis and growth. Front Oral Biol. 12:178-96 (2008).

Reardon W, Winter RM, Rutland P, Pulleyn LJ, Jones BM, Malcolm S: Mutations in the fibroblast growth factor receptor 2 gene cause Crouzon syndrome. Nat Genet. 8(1):98-103 (1994).

Roth DA, Gold LI, Han VK, McCarthy JG, Sung JJ, et al: Immunolocalization of transforming growth factor beta 1 , beta 2 , and beta 3 and insulin-like growth factor I in premature cranial suture fusion. Plast Reconstr Surg. 99(2):300-9 (1997)

Rouzier C, Soler C, Hofman P, Brennetot C, Bieth E, Pedeutour F: Ovarian dysgerminoma and Apert syndrome. Pediatr Blood Cancer. 50(3):696-8 (2008).

Rutland P, Pulleyn LJ, Reardon W, Baraitser M, Hayward R, et al: Identical mutations in the FGFR2 gene cause both Pfeiffer and Crouzon syndrome phenotypes. Nat Genet. 9(2):173-6 (1995).

Shen K, Krakora SM, Cunningham M, Singh M, Wang X, et al: Medical treatment of craniosynostosis: recombinant Noggin inhibits coronal suture closure in the rat craniosynostosis model. Orthod Craniofac Res. 12(3):254-62 (2009).

Shukla V, Coumoul X, Wang RH, Kim HS, Deng CX: RNA interference and inhibition of MEK-ERK signaling prevent abnormal skeletal phenotypes in a mouse model of craniosynostosis. Nat Genet. 39(9):1145-50 (2007).
Thomas GP, Wilkie AO, Richards PG, Wall SA: FGFR3 P250R mutation increases the risk of reoperation in apparent 'nonsyndromic' coronal craniosynostosis. J Craniofac Surg. 16(3):347-52 (2005).

Wang Y, Zhou X, Oberoi K, Phelps R, Couwenhoven $\mathrm{R}$, et al: p38 Inhibition ameliorates skin and skull abnormalities in Fgfr2 Beare-Stevenson mice. J Clin Invest. 122(6):2153-64 (2012).

Warren SM, Brunet LJ, Harland RM, Economides AN, Longaker MT: The BMP antagonist noggin regulates cranial suture fusion. Nature. 422(6932):625-9 (2003).

Wilkie AO: Bad bones, absent smell, selfish testes: the pleiotropic consequences of human FGF receptor mutations. Cytokine Growth Factor Rev. (2):187-203 (2005).

Wilkie AO: Cancer drugs to treat birth defects. Nat Genet. 39(9):1057-9 (2007)

Wilkie AO, Slaney SF, Oldridge M, Poole MD, Ashworth GJ, et al: Apert syndrome results from localized mutations of FGFR2 and is allelic with Crouzon syndrome. Nat Genet. 9(2):165-72. (1995).

Wilkie AO, Byren JC, Hurst JA, Jayamohan J, Johnson D, et al: Prevalence and complications of single-gene and chromosomal disorders in craniosynostosis. Pediatrics. 126(2):e391-400 (2010).

Woods RH, Ul-Haq E, Wilkie AO, Jayamohan J, Richards PG, et al: Reoperation for intracranial hypertension in TWIST1-confirmed Saethre-Chotzen syndrome: a 15-year review. Plast Reconstr Surg. 123(6):1801-10 (2009).

Yin L, Du X, Li C, Xu X, Chen Z, et al: A Pro253Arg mutation in fibroblast growth factor receptor 2 (Fgfr2) causes skeleton malformation mimicking human Apert syndrome by affecting both chondrogenesis and osteogenesis. Bone. 42(4):631-43 (2008).

Yokota M, Kobayashi Y, Morita J, Suzuki H, Hashimoto Y, et al: Therapeutic effect of nanogel-based delivery of soluble FGFR2 with S252W mutation on craniosynostosis. PLoS One. 9(7):e101693 (2014). 